\title{
PERDA DE SOLO EM DIFERENTES CULTURAS AGRÍCOLAS SOBRE LATOSSOLO VERMELHO NO MUNICÍPIO DE PATROCÍNIO, MG
}

\author{
Mariangela Garcia Praça Leite ${ }^{1}$, Maria Augusta Gonçalves Fujaco ${ }^{2}$, Gleidson Caetano da Silva ${ }^{3}$
}

\section{RESUMO}

Os processos erosivos, apesar de naturais, vêm sendo intensificados pelo uso inadequado do solo provocando a perdas anuais de bilhões de toneladas de solos férteis em todo o mundo. Assim, compreender este processo é fundamental para um desenvolvimento sustentável da atividade agrícola. Este trabalho avaliou as perdas de solo por erosão laminar em sete parcelas, sob diferentes tratamentos (mata; cultivo de soja, milho e cafeeiro, pastagem e solo exposto), em Latossolos vermelhos da Fazenda Esmeril, em Patrocínio, MG. As parcelas de solo exposto apresentaram os maiores valores de perdas de solo, com mais de $23 \mathrm{Mg} \mathrm{ha}^{-1}$ ano $^{-1}$. Em relação aos demais tratamentos, a mata apresentou os menores totais, aproximadamente 38\%; dentre as culturas, o milho (79\%), seguido da soja (68\%), foram os que apresentaram os maiores valores para as perdas de solo, bem superiores ao da área de cafezal e pasto, com $47 \% \mathrm{e}$ $45 \%$, respectivamente. Apesar do sistema de plantio direto nas culturas de soja e milho ter reduzido a produção de sedimentos nestas áreas, estas ainda continuam perdendo muito material durante as fases de preparação do solo e plantio. Já o valor elevado apresentado na cultura do cafeeiro é reflexo do grande espaçamento entre plantas.

Palavras-chave: erosão laminar, agricultura, perda de solo

\section{ABSTRACT \\ SOIL LOSS IN AGRICULTURE CROPS CULTIVATED IN OXISOLS OF THE MUNICIPALY OF PATROCÍNIO, MG}

Erosive processes, although natural, have been intensified by inadequate soil use causing billions of tones of annual fertile soil losses around the world. Thus, understanding these processes is fundamental for the sustainable development of agriculture activities. This study evaluated soil losses by laminar erosion in seven plots under different treatments (forest, soybean, corn and coffee, pasture and bare soil), in oxisols of the Esmeril Farm, in Patrocínio, MG. The plots of bare soil showed the highest values of soil loss, more than $23 \mathrm{Mg} /$ ha/year. When compared with the values obtained for the bare soil, the forest yielded the lowest total, approximately 38\%; among the crops, corn (79\%), followed by soybeans $(68 \%)$ were those with most elevated values for soil loss, significantly higher than coffee and pasture, with $47 \%$ and $45 \%$, respectively. Despite the fact that the tillage system used for soybean and corn cultures reduced the sediment production in these areas, they continue to lose a great amount of material during soil preparation and planting. The high value obtained for coffee plantation reflects the wide spacing of the plants in the field.

Keywords: laminar erosion, agriculture, soil loss

\section{Recebido para publicação em 18/03/2013. Aprovado em 23/06/2014.}

1- Doutora em Engenharia Civil. Geóloga. Professora Associada no UFOP/DEGEO email: garcia@degeo.ufo.br

2 - Msc. Em Recursos Naturais. Engenheira Zootécnica. Doutoranda no programa de Evolução Crustal e Recursos Naturais do DEGEO. Professora Assistente II na UFOP/DEGEO email: augusta@degeo.ufop.br

3- Geógrafo - Centro Universitário do Cerrado: email: gleisonssilva@yahoo.com.br 


\section{INTRODUÇ̃̃O}

A erosão laminar é um problema global e, apesar da dificuldade de se estimar com precisão as perdas de solo, sabe-se que a magnitude destas perdas tem causado sérias consequências econômicas e ambientais (GALE; HAWORTH, 2005). Este processo, apesar de natural, é acelerado pela ação antrópica com a intensificação das técnicas de manejo rural, com o intuito de aumentar a produtividade (THOMAZ, 2009). Tal fato tem mudado severamente a paisagem, marcada pela degradação ambiental. A erosão acentuada consiste em um dos principais problemas ambientais causados pela atividade agrícola, especialmente em regiões tropicais, aonde a erosão hídrica vem ocasionando a perda da camada mais fértil dos solos (PRASANNAKUMAR et al., 2012), principalmente em Latossolos, que sofrem intenso processo erosivo quando submetidos a sistemas de preparo e cultivos impróprios (KNAPEN et al., 2007b).

O modelo brasileiro de ocupação da terra produtiva tem sido um processo desordenado em todo o país, com a retirada da vegetação para a prática de diversos cultivos e instalação de pastagens, não levando em conta áreas sensíveis à degradação ambiental (CASTRO; QUEIROZ NETO, 2009). O preparo inadequado ou excessivo do solo para a implantação de culturas favorece a ocorrência da erosão, um importante fator de degradação das terras agrícolas e do meio ambiente no Brasil e no Mundo.

As camadas superficiais do solo, em geral as mais férteis, são as primeiras a serem degradadas. $\mathrm{Na}$ erosão hídrica, o impacto das gotas de chuva ou da água de irrigação no solo exposto causa desagregação de sua estrutura e o desprendimento das partículas menores, que, ao serem transportadas, carregam nutrientes e defensivos a elas adsorvidos e também matéria orgânica. No local de produção, nos casos de erosão mais severa, sementes, mudas e até mesmo plantas em estágio inicial de desenvolvimento podem ser arrancadas. Em conjunto, essas perdas levam ao empobrecimento do solo, diminuindo sua capacidade de produzir boas safras e, consequentemente, aumentando os custos de produção, o que condiciona menores rendimentos para o produtor rural. Hernani et al. (2002) registraram que as perdas anuais de solo causadas pela erosão em áreas ocupadas por lavouras e pastagens no Brasil, na ordem de 830 milhões de toneladas, causam um prejuízo total ao Brasil superior a US $\$ 4,2$ bilhões por ano.

$O$ processo de expansão agrícola na região de Patrocínio, MG, se intensificou juntamente com o processo de mecanização da agricultura na década de 70 em toda a região no noroeste mineiro, trazendo consigo várias técnicas de manejo a serem empregadas visando maior produtividade. Provocando, dentre outros problemas, o empobrecimento da fertilidade, compactação e erosão dos solos, contaminação química das águas e da biota e o rebaixamento do lençol freático nos vales em "veredas", onde as planícies aluviais estão sendo drenadas pelos projetos de irrigação (BACCARO, 1990). A determinação do risco de erosão e a previsibilidade da perda de solo são subsídios importantes para o planejamento agrícola e ambiental de uma região (LIMA et al., 1992). Para tal, é indispensável à avaliação das propriedades físicas do solo sob diferentes sistemas de preparo (TORMENA et al., 2002). Neste contexto, o objetivo geral com a realização deste trabalho foi determinar a influência da ocupação agrícola e do manejo de diferentes culturas nos processos da perda do solo por erosão laminar em Latossolo de Patrocínio, MG.

\section{MATERIAL E MÉTODOS}

A pesquisa foi realizada na Fazenda Esmeril (FUNCECP), localizada no município de Patrocínio (Latitude18 $8^{\circ} 7^{\prime} 15.52^{\prime \prime S}$, Longitude: 4659'7.74'O; e Latitude: 1858'16.23”'S, Longitude: $46^{\circ} 57^{\prime} 22.35^{\prime \prime}$ ) ) na porção oeste de Minas Gerais, na zona fisiográfica do Alto Paranaíba e possuindo uma área de cerca de 205 ha. A área da fazenda é destinada a atividade agrícola, tanto para sua auto-sustentabilidade como para fins educacionais, já que em seu interior

\section{REVENG}


funciona a Escola Agrotécnica Sérgio de Freitas Pacheco (EASFP), além do Centro Universitário do Cerrado - Patrocínio (UNICERP), formando o conjunto da Fundação Comunitária, Educacional e Cultural de Patrocínio

Em termos geomorfológicos, a área de estudo pertence às Áreas de Relevo Suave, que se encontram localizadas nas porções sul e sudoeste do município de Patrocínio, em uma altitude média de 890 m (MACHADO, 2001). O clima da região segundo a classificação de Köppen, é do tipo Aw, ou seja, possui um inverno seco e um verão chuvoso, dominado predominantemente pelos sistemas intertropicais e polares. Os solos são profundos, com a predominância de Latossolos Vermelhos, férricos e distróficos, proveniente da decomposição dos micaxistos do Grupo Araxá (MACHADO, 2001).

Aproximadamente $60 \%$ da área da Fazenda Esmeril destina-se ao cultivo experimental com foco educacional, onde se efetua os cultivos de soja, milho, horticulturas, fruticulturas e cafeeiro (Quadro1). A propriedade possui 14,0 ha destinados a Área de Preservação Permanente APP's, sendo que a maior parte encontra-se como áreas de mata ciliar/de galeria na margem do Córrego Enxó; o restante encontra-se no entorno das quatro represas da propriedade e no entorno de uma nascente. Em alguns trechos, principalmente à montante do Córrego Enxó, encontra-se em razoável estado de conservação; os outros trechos, apesar de estar cercada para evitar a entrada de bovinos (na margem do Córrego Enxó), é nítido o estado de degradação das águas. As outras três represas (lado oeste) encontram-se em melhor estado de conservação, já que praticamente não são utilizadas.

As variedades de cafeiro cultivadas são a Catuaí 99 e 144 e Acaiá Cerrado. A calagem é executada conforme a indicação da análise do solo, o sistema de plantio é feito em nível de terraceamento, com o espaçamento de $4,0 \times 1,0 \mathrm{~m}$ e densidade de 2500 pés/ha. A capina e a colheita são manuais e o controle de pragas e doenças é realizado com a aplicação manual de defensivos. O cronograma do processo produtivo está disposto na Quadro2.

A área cultivada com soja utiliza sementes das variedades Garantia e Conquista, sob o sistema de plantio direto. A colheita da soja é mecanizada e o controle de pragas e doenças é realizado com o uso de defensivos aplicados manualmente (Quadro2).

O cultivo do milho na Fazenda Esmeril utiliza sementes das cultivares Fort (Syngenta) e DKD 350 , em plantio direto, com o espaçamento de $0,8 \mathrm{~m}$ entre linhas e com a densidade de cinco sementes por metro linear $\left(20 \mathrm{~kg} \mathrm{ha}^{-1}\right)$. O sistema de colheita do milho também é mecanizado e o controle de pragas e doenças é realizado com o uso de defensivos aplicados manualmente (Quadro2). Para o cafeeiro, milho e soja a calagem é realizada conforme resultados da análise de solo.

Quadro 1. Caracterização das culturas na Fazenda Esmeril, sua área cultivada e o sistema utilizado de plantio.

\begin{tabular}{lcc}
\hline Cultura & Área (ha) & Sistema \\
\hline Soja & 73,1 & Sequeiro \\
Milho & 19,36 & Sequeiro \\
Cafeeiro & 26,5 & Sequeiro \\
Pasto & 4,59 & Piquetes \\
Fruticultura & 3,3 & Irrigado \\
Horticultura & 2,98 & Hidropônico/Irrigado \\
Silvicultura & 1,5 & Em renque \\
\hline
\end{tabular}


Quadro 2. Cronograma do Processo Produtivo de Cafeeiro (C), Soja (S) e Milho (M) da Fazenda Esmeril

\begin{tabular}{|c|c|c|c|c|c|c|c|c|c|c|c|}
\hline \multirow{2}{*}{ ATIVIDADES } & \multicolumn{11}{|c|}{ MESES } \\
\hline & $\mathbf{J}$ & $\mathbf{F}$ & $\mathbf{M}$ & A & M & $\mathbf{J}$ & $\mathbf{J}$ & A & S & o & $\mathbf{N}$ \\
\hline Aplicação de calcário & & & & & & & S, M & & & & \\
\hline $\begin{array}{l}\text { Tratamento de } \\
\text { semente }\end{array}$ & & & & & & & & & & $\mathbf{S}$ & $\mathbf{M}$ \\
\hline Dessecação & & & & & & & & & & $\mathbf{S}$ & $\mathbf{M}$ \\
\hline Plantio & & & & & & & & & & $\mathbf{S}$ & $\mathbf{M}$ \\
\hline $\begin{array}{l}\text { Controle de pragas e } \\
\text { doenças }\end{array}$ & C & C & C & C & C & C & C & C & C & $\mathrm{C}, \mathrm{S}$ & C, M \\
\hline Capina & & & & & & C & & & & & $\mathbf{C}$ \\
\hline $\begin{array}{l}\text { Aplicação } \\
\text { Fertilizantes }\end{array}$ & & C & C & & & & & & & $\mathbf{S}$ & $\mathbf{M}$ \\
\hline Colheita & & & $\mathbf{M}$ & $\mathbf{S}, \mathbf{M}$ & $\mathrm{C}$ & & & & & & \\
\hline
\end{tabular}

Os dados pluviométricos foram obtidos junto à estação meteorológica de Patrocínio, que forneceu uma série histórica de 42 anos, de 1968 a 2009.

Para avaliar o processo de erosão laminar, utilizou-se a metodologia sugerida por Guerra e Oliveira (1995), que consiste na implantação da estação experimental com parcelas (plots) de $1 \mathrm{~m}$ $\mathrm{x} 10 \mathrm{~m}\left(10 \mathrm{~m}^{2}\right)$ para coleta da água do escoamento superficial (runoff) e do material em suspensão. $\mathrm{O}$ isolamento das parcelas foi feito por tábuas de madeira com $3 \mathrm{~cm}$ de espessura. Os solos que margeiam as parcelas, depois de enterradas as tabuas, foram comprimidos usando um compactador manual visando à impermeabilização, buscando o isolamento das parcelas. A coleta do material foi feita por uma calha de PVC de $100 \mathrm{~mm}$, ligada por meio de uma mangueira e um sifão a um galão de 50 litros, que foram devidamente enterrados no solo, em uma profundidade de aproximadamente $1,20 \mathrm{~m}$.

Os tratamentos foram: mata (parcela 1), cultivo de soja (parcela 2), cafezal (parcela 3), cultivo de milho (parcela 4), pasto (parcela 5) e solo exposto (parcelas 6 e 7). Determinou-se a declividade de cada parcela utilizando-se um nível topográfico com mira.

Após a instalação das parcelas em dezembro de 2008 , foram realizadas 24 coletas quinzenais de sedimentos e águas, sendo a primeira em 08/01/2009 e a última em 03/01/2010.

Uma amostra com cerca de $1 \mathrm{~kg}$ foi retirada do centro da parcela, identificada e armazenada em câmara úmida para análises. Em laboratório, todas as amostras coletadas foram colocadas em uma vasilha plástica, secadas e colocadas em uma capela a $40{ }^{\circ} \mathrm{C}$. Em seguida, as amostras foram desagregadas em gral com um pistilo, pesadas e quarteladas. Um dos quartis foi reservado como testemunho e os demais utilizados para as análises de caracterização dos solos. Foram realizadas análises granulométricas via seca e via úmida com densímetro, determinação dos limites de plasticidade e liquidez, total de matéria orgânica (perda por calcinação) e ensaio de estabilidade de agregados. Ainda no campo, foi avaliada a permeabilidade do solo utilizando-se um permeâmetro Guelph.

\section{RESULTADOS E DISCUSSÃO}

A região estudada apresenta uma pluviosidade anual média de $1.647 \mathrm{~mm}$, tendo chovido $1.951 \mathrm{~mm}$ durante o período monitorado, aproximadamente $17 \%$ a mais que a média histórica. As maiores diferenças ocorreram nos meses de outubro, março e dezembro. Segundo Knapen et al. 
(2007a), as variações temporais da pluviosidade são as grandes responsáveis pelas mudanças na umidade e consolidação do solo, crescimento das raízes, decomposição dos resíduos e a presença de crostas microbianas, fatores estes que controlam a variabilidade espacial da resistência à erosão de um determinado solo. Os resultados obtidos neste estudo corroboram esta assertiva (Quadros 3 e 4). No Quadro 3 estão listados os resultados encontrados para a declividade, permeabilidade e demais características do solo de cada parcela.

No Quadro 4 encontram-se os dados com os totais de água e sedimentos coletados durante as amostragens quinzenais. Verificou-se que os solos amostrados são arenosos, com pouca argila (entre 5 e 6,5\%) e baixos teores de matéria orgânica $(0,69$ a $0,9 \%)$. O solo encontrado na mata é o que apresentou o maior teor de matéria orgânica e permeabilidade, ficando nos solos expostos a menor permeabilidade encontrada, devido a sua compactação.

Nos resultados de perda de solo por parcela (Quadro 4), observa-se que a área de mata produziu os menores totais, $38 \%$ do material erodido nas parcelas de solo exposto. Dentre as culturas, o milho $(79 \%)$, seguido da soja (68\%) foram os que apresentaram os valores maiores para as perdas de solo, bem superiores aos da área do cafezal e ao pasto, $47 \%$ e $45 \%$ de perdas, respectivamente, quando comparado com o solo exposto. As maiores perdas registradas nas culturas de soja e milho ocorreram com a chegada das primeiras chuvas em outubro (Quadro 4). Já a mata, o pasto e o solo exposto tiveram seu ápice de perda de solo no período de maior precipitação (última quinzena de dezembro). $\mathrm{Na}$ área de cafezal a maior perda foi registrada na primeira quinzena de novembro, após a segunda capina (Quadro 2). Vale destacar ainda que as declividades das parcelas com as culturas de soja, milho e cafeeiro eram as menores (Quadro 3), ou seja, com maiores declives a produção de sedimentos tende a ser superior aos valores encontrados.

Os valores de perda de solo por hectare encontram-se no Quadro 5, valores estes muito semelhantes aos encontrados na literatura para estas culturas (BERTOL; MIQUELLUTI, 1993; HERNANI et al., 2002; BEUTLER et al., 2003; COGO et al., 2003; CARVALHO et al. 2007).

Quadro 3. Resultados dos ensaios e análises do solo $(\mathrm{LL}=$ limite de liquidez e $\mathrm{DMP}=$ diâmetro médio ponderado)

\begin{tabular}{|c|c|c|c|c|c|}
\hline & $\begin{array}{c}\text { Declividade } \\
(\%)\end{array}$ & $\begin{array}{l}\text { Permeabilidade } \\
\qquad(\mathrm{mD})\end{array}$ & $\begin{array}{c}\text { Matéria } \\
\text { Orgânica (\%) }\end{array}$ & $\begin{array}{l}\text { Limite de } \\
\text { Liquidez }\end{array}$ & $\begin{array}{c}\text { Diâmetro } \\
\text { Médio } \\
\text { Ponderado }\end{array}$ \\
\hline $\begin{array}{l}\text { PARCELA } 01 \\
\text { (Mata) }\end{array}$ & 9,31 & 0,069 & 1,00 & 58,31 & 1,23 \\
\hline $\begin{array}{l}\text { PARCELA } 02 \\
\text { (soja) }\end{array}$ & 5,88 & 0,023 & 0,80 & 49,60 & 1,47 \\
\hline $\begin{array}{l}\text { PARCELA } 03 \\
\text { (cafezal) }\end{array}$ & 5,29 & 0,034 & 0,79 & 47,73 & 1,01 \\
\hline $\begin{array}{l}\text { PARCELA } 04 \\
\text { (milho) }\end{array}$ & 6,27 & 0,034 & 0,93 & 44,93 & 1,23 \\
\hline $\begin{array}{l}\text { PARCELA } 05 \\
\text { (pasto) }\end{array}$ & 9,21 & 0,025 & 0,88 & 46,79 & 1,22 \\
\hline $\begin{array}{l}\text { PARCELA } 06 \\
\text { (solo exposto) }\end{array}$ & 9,61 & 0,011 & 0,73 & 50,05 & 1,14 \\
\hline $\begin{array}{l}\text { PARCELA } 07 \\
\text { (solo exposto) }\end{array}$ & 9,22 & 0,007 & 0,70 & 49,00 & 1,10 \\
\hline
\end{tabular}




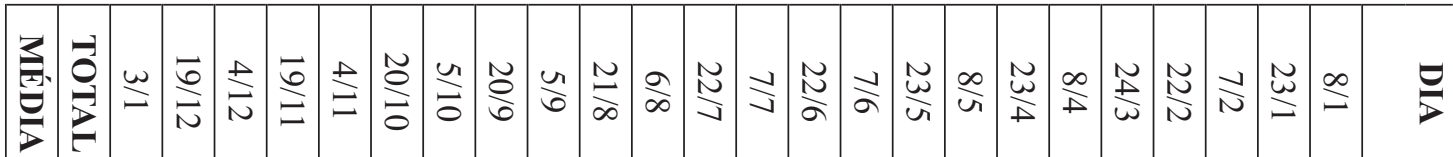

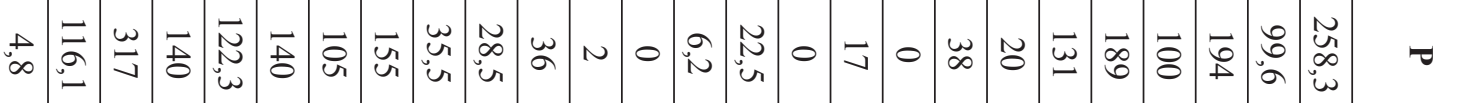

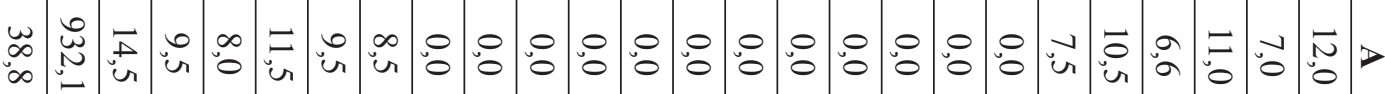

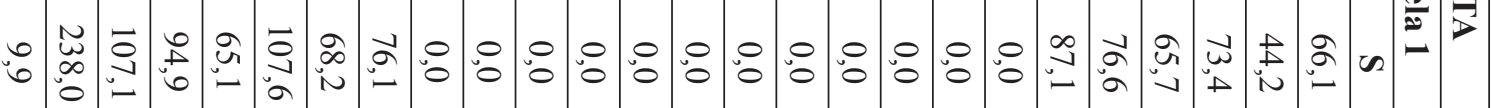

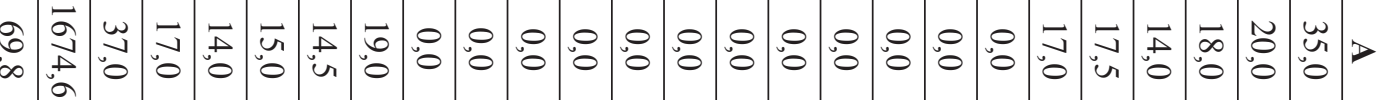

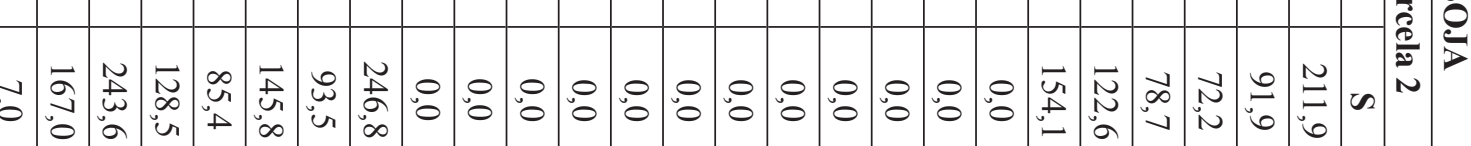

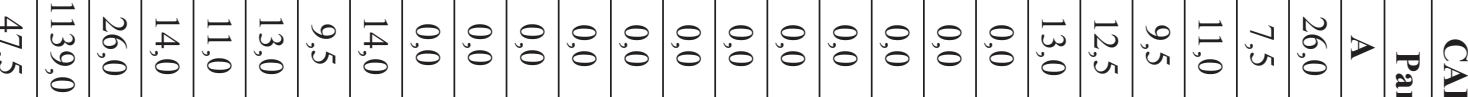

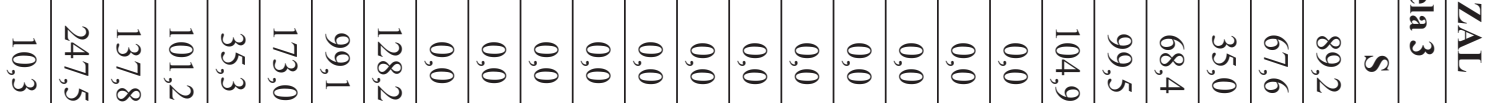

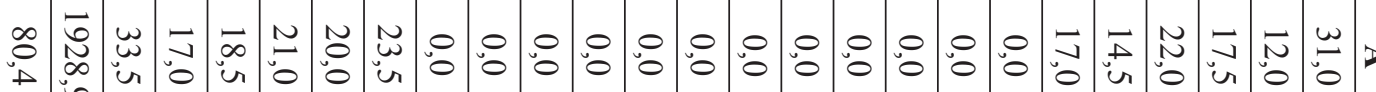

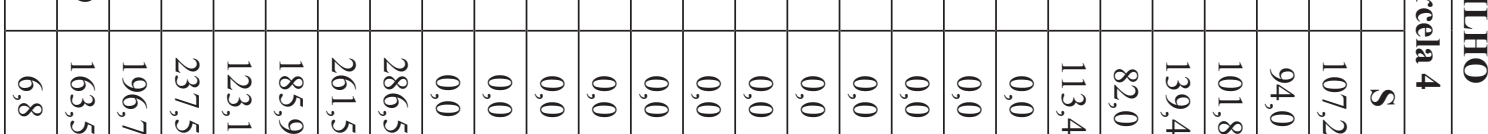

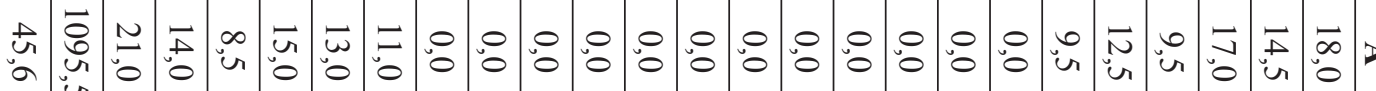

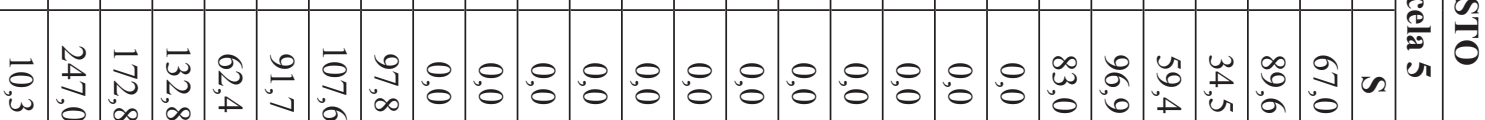

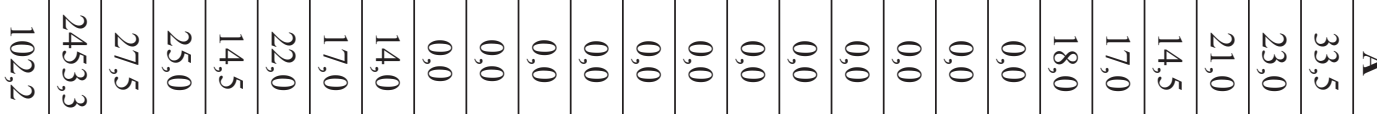

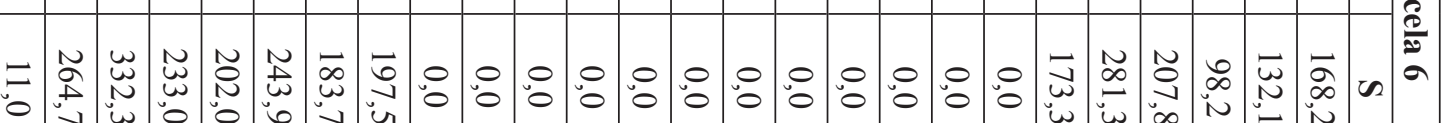

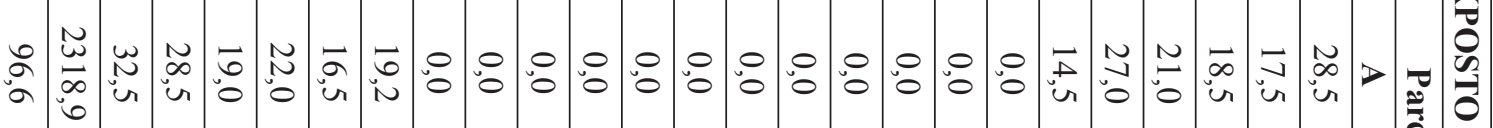


Quadro 5. Estimativa da perda de solo, em $\mathrm{mg} \mathrm{ano}^{-1} \mathrm{ha}^{-1}$, e perda total na Fazenda

\begin{tabular}{lccc}
\hline & $\begin{array}{c}\text { PERDA POR } \\
\text { HECTARE (mg/ano) }\end{array}$ & $\begin{array}{c}\text { HECTARES } \\
\text { PLANTADOS }\end{array}$ & $\begin{array}{c}\text { TOTAL DE PERDA NA } \\
\text { FAZENDA (ma/ano) }\end{array}$ \\
\hline MATA & $9,32 \mathrm{E}+06$ & 14 & $13,0 \mathrm{E}+07$ \\
\hline SOJA & $16,7 \mathrm{E}+06$ & 73,1 & $122,0 \mathrm{E}+07$ \\
\hline CAFÉZAL & $11,4 \mathrm{E}+06$ & 19,36 & $22,1 \mathrm{E}+07$ \\
\hline MILHO & $19,3 \mathrm{E}+06$ & 26,5 & $51,1 \mathrm{E}+07$ \\
\hline PASTO & $11,0 \mathrm{E}+06$ & 4,59 & $5,03 \mathrm{E}+07$ \\
\hline SOLO EXPOSTO & $24,53 \mathrm{E}+06$ & $?$ & $?$ \\
\hline SOLO EXPOSTO & $23,19 \mathrm{E}+06$ & $?$ & $?$ \\
\hline
\end{tabular}

O plantio direto é, sem dúvida, a técnica de manejo de solo mais adequada para o controle da erosão (HERNANI et al., 2002; CAMARA; KLEIN, 2005), inclusive demonstrando uma tendência de estabilização das perdas de solo ao longo dos anos (HERNANI et al., 2002). Mesmo assim, o não revolvimento do solo no plantio direto, aliado ao tráfego de máquinas, pode provocar alterações na sua estrutura que podem reduzir a infiltração de água, modificando a sua dinâmica nesse sistema (CAMARA; KLEIN, 2005).

Os sistemas de preparo do solo promovem modificações significativas nas propriedades físicas como a agregação do solo (CASTRO FILHO et al., 1998), densidade (DE MARIA et al., 1999) e a porosidade do solo, que pode ser drasticamente reduzida (Dias Jr.; Pierce, 1996). O período crítico é durante o preparo do solo e a semeadura, quando o solo encontra-se descoberto, exatamente o período de maior produção de sedimentos encontrado para os cultivos de soja e milho. No caso do cafezal, os valores obtidos para perda de solo estão bem acima dos valores obtidos por Carvalho et al. (2007) para os tratamentos de capina manual e uso de herbicidas, provavelmente devido ao grande espaçamento entre os pés de cafeeiro utilizado na Fazenda Esmeril (2500 pés/ha), quando comparado com os existentes nos tratamentos estudados pelos autores (4444 pés ha- ${ }^{-1}$ ). No que diz respeito aos valores obtidos para a mata, os valores a colocam em uma perda média, segundo os valores propostos por Young (1997). Já o pasto apresentou valores relativamente mais baixos que os encontrados na literatura, reflexo da ausência de gado extensivo na fazenda.

As grandes perdas de solo agriculturável no Brasil e no mundo têm causado prejuízos imensos, não só econômicos como também ambientais. Uma das formas de se tentar reduzir estes prejuízos é através de pesquisas como o presente projeto, que buscam um maior entendimento dos processos erosivos nas áreas agrícolas. Este foi um dos primeiros trabalhos neste sentido realizado na região de Patrocínio e o único na Fazenda Esmeril.

\section{CONCLUSÕES}

- O aumento na erosão laminar, ocasionado pela retirada da mata nativa, seja para plantio de diversas culturas ou para a implementação de pastos, bem como acelerado desgaste do solo quando este é deixado exposto por longos períodos e mesmo na entressafra;

- O plantio direto, utilizado na fazenda, apesar de reduzir as perdas de solo carece ainda de aprimoramento, especialmente no que tange a proteção do solo durante a fase de preparação e plantio;

- A cultura de cafeeiro deveria ser adensada, reduzindo as áreas expostas, o que minimizaria o processo erosivo, aumentando paralelamente a produção. 


\section{AGRADECIMENTOS}

Os autores desejam expressar seus agradecimentos à FAPEMIG, que financiou o projeto, e aos Centros Tecnológico do Cerrado (CET Cerrado) e Universitário do Cerrado - Patrocínio (UNICERP), que gentilmente cederam a área para estudos e forneceram apoio logístico aos trabalhos de campo.

\section{REFERÊNCIAS BIBLIOGRÁFICAS}

BACCARO, C.A.D. Estudo dos processos geomorfológicos de escoamento pluvial em área de Cerrado, Uberlândia-MG. Tese (Doutorado em Geografia Física) FFLCH/USP, 1990.

BERTOL, I.; MIQUELLUTI, D.J. Perdas de solo, água e nutrientes reduzidas pela cultura do milho. Pesquisa Agropecuária Brasileira, Brasília, v.28, n.10, p.1205- 1213, 1993.

BEUTLER, J.F.; BERTOL,I.; VEIGA,M.; WILDNER, L.P. Perdas de solo e água num Latossolo Vermelho aluminoférrico submetido a diferentes sistemas de preparo e cultivo sob chuva natural. Revista Brasileira de Ciência do Solo, Viçosa, v.27, n.3, p. 509-517, 2003.

CAMARA, R.K. e KLEIN, V.A. Escarificação em plantio direto como técnica de conservação do solo e da água. Revista Brasileira de Ciência do Solo, v.29, p.789-796, 2005.

CARVALHO, R.; SILVA, M.L.N.; AVANZI, J.C.; CURI, N; SOUZA, F.S. Erosão hídrica em latossolo vermelho sob diversos sistemas de manejo do cafeeiro no sul de Minas Gerais. Ciência Agrotec. Lavras, v.31, n.6, p.1679-1687, 2007.

CASTRO FILHO, C.; MUZILLI, O.; PODANOSCHI, A.L. Estabilidade de agregados e sua relação com o teor de carbono orgânico num latossolo roxo distrófico, em função de sistemas de plantio, rotação de culturas e métodos de preparo das amostras. Revista Brasileira de Ciência do Solo, v.22, p.527-538, 1998.

CASTRO, S.S., QUEIROZ NETO, J.P. Soil
Erosion in Brazil from Coffee to the Present-day Soy Bean Production. Developments in Earth Surface Processes, 13: 195-221. 2009.

COGO, N.P.; LEVIEN, Renato.; SCHWARZ, Ricardo. A. Perdas de solo e água por erosão hídrica por método de preparo, classes de declividade e níveis de fertilidade do solo. Revista Brasileira Ciência do Solo, Campinas, n.27, p.743-753, 2003.

DE MARIA, I.C.; CASTRO, O.M.; DIAS, H.S. Atributos físicos do solo e crescimento radicular de soja em latossolo roxo sob diferentes métodos de preparo do solo. Revista Brasileira de Ciência do Solo, v.23, p.703-709, 1999.

DIAS Jr, M.S.; PIERCE, F.J. O processo de compactação do solo e sua modelagem. Revista Brasileira de Ciência do Solo, v.20, p.175-182, 1996.

GALE, S.J., HAWORTH, R.J. Catchment-wide soil loss from pre-agricultural times to the present: transport- and supply-limitation of erosion. Geomorphology, 68 (1): 314-333. 2005.

HERNANI, L.C.; SALTON, J.C.; FABRÍCIO, A.C.; DEDECEK, R.; ALVES Jr., M. Perdas por erosão e rendimentos de soja e trigo em diferentes sistemas de preparo de um Latossolo Roxo de Dourados (MS). Revista Brasileira de Ciência do Solo, v.21, 667-676, 1997.

KNAPEN, A., POESEN, J., GOVERS, G., GYSSELS, G., NACHTERGAELE, J. Resistance of soils to concentrated flow erosion: A review. Earth-Science Reviews, 80 (1-2):75-109. 2007a.

KNAPEN, A., POESEN J., BAETS, S. Seasonal variations in soil erosion resistance during concentrated flow for a loess-derived soil under two contrasting tillage practices. Soil and Tillage Research, 94, (2):425-440, 2007b.

LIMA, E.R.V.; KUX, H.J.H.; SAUSEN, T.M. Sistema de Informações Geográficas e técnicas de sensoriamento remoto na elaboração de mapas de risco de erosão no sertão da Paraíba. Revista 
Brasileira de Ciência do Solo, v.16, n.2, p.257263, 1992.

MACHADO, M.D.G. As unidades morfológicas e a estruturação da paisagem no município de Patrocínio - Minas Gerais. 82f. Dissertação (Mestrado em Geografia) - Pós Graduação em Geografia, Universidade Federal de Uberlândia, Uberlândia, Minas Gerais, 2001.

PRASANNAKUMAR, V., VIJITH, H., ABINOD, S., GEETHA, N. Estimation of soil erosion risk within a small mountainous sub-watershed in Kerala, India, using Revised Universal Soil Loss Equation (RUSLE) and geo-information technology. Geoscience Frontiers, 3(2): 209-215. 2012.
TORMENA, C.A.; BARBOSA, M.C.; COSTA, A.C.S.; GONÇALVES, A.C.A. Densidade, porosidade e resistência à penetração em Latossolo Vermelho distrófico cultivado sob diferentes sistemas de preparo do solo. Scientia Agricola, v.59, p.795-801, 2002.

THOMAZ, E.L. The influence of traditional steep land agricultural practices on runoff and soil loss. Agriculture, Ecosystems e Environment, 130 (12): 23-30, 2009.

YOUNG, A. Agroforestry for soil management. 2. ${ }^{\text {ed }}$ Wallingford: ICRAF and CAB International, 1997. 320p. 